\title{
Will the economic growth benefit public health? Health vulnerability, urbanization and COVID-19 in the USA
}

\author{
Ye Fan ${ }^{1} \cdot$ Ming Fang $^{2} \cdot$ Xin Zhang ${ }^{3}$ Yongda Yu ${ }^{1}$
}

Received: 2 March 2021 / Accepted: 7 December 2021 / Published online: 22 January 2022

(c) The Author(s), under exclusive licence to Springer-Verlag GmbH Germany, part of Springer Nature 2022

\begin{abstract}
Economic growth has a significant impact on health vulnerability primarily through the process of urbanization. This paper conducts a pioneer study by analyzing the impact of regional economic growth and urbanization on the public health vulnerability in the 51 states and territories of the USA from 2011 to 2018 with a fixedeffect panel data regression model. We construct an epidemiological vulnerability index (EVI) using regional smoking, diabetes, obesity, and hypertension, collect CDC social vulnerability index (SVI) as state-level public health vulnerability status, and use COVID-19 to test the actual effect of health vulnerability. The preliminary results show that higher regional economic growth is related to lower EVI and SVI, while urbanization is positively associated with regional health vulnerability and the severity of COVID-19 from case rate and death rate. Robustness check with unemployment shows the same result. We conclude that economic growth is related to lower public health vulnerability, and urbanization has negative public health benefits. Our finding indicates an urgent need to balance the externalities generated by economic development and urbanization trends on public health vulnerability by promoting reasonable medical resource distribution, health practices and safety, improving social and environmental justice, and other health management measures.
\end{abstract}

JEL Classification I10 - I15 · I18 · J18 · R11

Yongda Yu

yuyongda@mail.tsinghua.edu.cn

Ye Fan

fanyecup@foxmail.com

Ming Fang

sliverfrank@foxmail.com

Xin Zhang

xinzi@umich.edu

1 School of Public Policy and Management, Tsinghua University, Beijing, China

2 School of Economics and Management, China University of Petroleum (Beijing), Beijing, China

3 School of Public Health, University of Michigan, Ann Arbor, United States 


\section{Introduction}

As a major law, economic development and urbanization change public lifestyle and improve the living standard of the people at unimaginable trends, but the overall health vulnerability of the population has also changed. In regional sustainable and moderate development, economic development, and public health play an essential role (He et al. 2018; Jackson et al. 2004; Li et al. 2021), and the externality of economic growth and urbanization is closely associated with public health (Kunze 2014). It is worthwhile to quantify the relationship inside.

Economic development improves public health both directly and indirectly through prolonged life expectancy (Kunze 2014), lower mortality (Falagas et al. 2009), improved food and water safety, access to better healthcare services, and medical treatment (Catalano et al. 2011). However, economic prosperity, especially regarding urbanization, may pose new challenges to regional health. For example, regional agglomeration causes crowded housing, reduced places for physical exercise, increased fast-food, alcohol, air pollution, and drug consumptions (Patil 2014), industrial and traffic noise (Schaffer et al. 2020), contaminated drinking water and soil (Yousaf et al. 2016), and even vicious cycle of poverty and poor health on vulnerable populations (Karaye and Horney 2020). Consequently, the challenge of clarifying the intrinsic relationship of economic development and public health appears to be a hotspot of academia globally.

On measuring public health, traditional health indicators (i.e., life expectancy, mortality, and morbidity) alone are insufficient to picture current health status or predict the future without considering the underlying risks factors (Banks and Smith 2012). An increasing number of studies apply the health vulnerability concept in the evaluation of economic development, disaster policy, and environmental management (Briguglio et al. 2009; Eakin and Luers 2006), and the community vulnerability to infectious diseases (e.g., malaria, Ebola, and SARS-CoV-2) (Khazanchi et al. 2020; Kienberger and Hagenlocher 2014; Stanturf et al. 2015). However, few studies have directly examined the relationship between economic development and health vulnerability.

Our research broadens the existing literature by introducing the health vulnerability concept to evaluate economic growth and urbanization. We construct an epidemiological vulnerability index (EVI) with validated public health data in the USA during 2011-2018 and extract social vulnerability index (SVI) from the US Centers for Disease Prevention and Control (CDC) as two public health indicators. Moreover, we use COVID-19 pandemic data to validate the vulnerability to a public health crisis. The empirical results of the theoretical panel regression model show economic growth is associated with lower public social vulnerability (Anand and Ravallion 1993; Biggs et al. 2010; Granados and Ionides 2008), while urbanization increases local vulnerability significantly. The model is tested through robustness checks with the unemployment rate in the end.

This paper is organized as follows. We briefly conducted a comprehensive literature review in the field of public health and economic growth in Sect. 2. Section 3 contains the methods, the database, and the construction of variables. Section 4 
describes the empirical results and robustness checks. In Sect. 5, conclusions are presented.

\section{Theories}

Economic development is a resource integration process that leads to urbanization and has effects on public health. It is generally agreed that the two components are inseparable: economic growth is increasingly advancing urbanization, and urban regions gain fast economic growth rates from individuals with advanced technology (Batabyal and Nijkamp 2020), and throughout history, regions with high population agglomeration have always been important economic growth centers (Islam 2020). However, there is no consistent answer in the literature on the interaction between health and economic development.

Numerous studies successfully quantify the positive effect of exogenous health improvement from productivity, output per capita, and general GDP growth. For instance, cumulative economic growth is the major determinant of the declined mortality rate in the past century in the USA (Brenner 2005). Economic growth is also related to increased life expectancy and lower infant mortality (Majeed and Gillani 2017). The increase in national and individual income corresponds to longer life expectancy (Babones 2008) through higher income provides access to better healthcare resources, food choices, housing, and living environment (Brenner 2005). Consequently, with the development of the economy, increased life expectancy in the USA has added \$3.2 trillion a year to gross domestic product since the 1970s (Murphy and Topel 2006), and economic development promotes the further accumulation of health capital and creates a positive loop for developmental sustainability (Barro 1999). In general, the economy improves public health at both macro- and micro-levels.

What's more, economic development does not necessarily lead to positive health effects but brings new challenges to public health. In Sweden, the positive relationship between economic growth and health progress (i.e., mortality and life expectancy) weakened and eventually reversed in the second half of the twentieth century (Granados and Ionides 2008). There is an inverted U-shaped relationship between economic development and cardiovascular disease mortality among 27 European countries from 2003 to 2014 (Spiteri and von Brockdorff 2019). Environmental factors, socioeconomic status, and lifestyle have more adverse impacts on urban health (Thornton 2002). Tapia Granados (2008) find chronic processes evolved to more deaths during the economic upturn through higher traffic volume, tobacco consumption, alcohol consumption, acute respiratory disease, and even stress. However, the traditional macro-health indicators (e.g., life expectancy, mortality, and morbidity) omit the mechanisms that lay between adverse health effects and economic development by failing to add the epidemiological and social determinants of health. That explains why a seemingly fine community does not respond well when facing a pandemic hit as COVID-19. Therefore, there is a need to add indicators of vulnerability to public health studies in the literature. 
In measuring public health status, vulnerability is a critical indicator that describes a population from a holistic exposure-risk view that traditional macroindicators failed to reveal. Its inclusiveness and versatility make vulnerability analysis popular in different disciplines, and most of them, especially in disaster management, refer to this general formula: Risk=Hazard * (Vulnerability-Resources), where Risk is the probability or estimated loss, Hazard is the main condition or object that causes the loss, Vulnerability is the likelihood of being affected, and Resources are the assets that can help dimmish the effect of hazards (https://www. atsdr.cdc.gov). Disaster management studies use the vulnerability to measure the community's mortality and direct economic loss in the face of specific hazardinduced natural disasters and found the economic development is related with lower vulnerability to disasters (Ford et al. 2006). Environmental vulnerability shows that economic development, natural or social factors could affect the sustainability of ecological systems, such as species survival and habitat loss (He et al. 2018; Jackson et al. 2004). The definition of social vulnerability touches base on some socioeconomic determinants of health and is a real-time reflection and prediction of population health status (Khazanchi et al. 2020; Kienberger and Hagenlocher 2014; Stanturf et al. 2015). However, few studies directly examined the relationship between economy and health vulnerability with epidemiological characteristics, which makes our study pioneering research on this topic.

In this paper, we aim to break down the two-sided effect of economic development on public health and fit the general vulnerability assessment criteria into the current COVID-19 pandemic. In this case, our hypothesis is that the economic development brings the Resources (medical, housing, health information, etc.), but also increases the Vulnerability from various aspects (unhealthy lifestyle, income disparities, demographic characters, environmental pollutions, which leads to more preexisting medical conditions, etc.). Our main objective is to examine the relationship between economic development and the Vulnerability and Resources and how they associate with COVID-19 status. Since the health vulnerability index is a comprehensive concept made out of essential epidemiological and social indicators, it will help us understand how much economic growth will affect each aspect of public health vulnerability determinants. Therefore, we propose the following two hypotheses:

H1 Economic growth decreases the public health vulnerability.

H2 Urbanization increases public health vulnerability.

\section{Method and variables}

\subsection{Method}

Trying to comb the entangled public health effects of economic development, this paper integrates the three main elements, i.e., public health, economic growth, and urbanizations, into a fixed-effect panel regression model while controlling 
confounders that may potentially affect the public health vulnerability. Due to the insufficient time span of the sample in this article (2011-2018), the statistical interval of some explanatory variable data is longer, so it is not sufficient to identify the effect of explanatory variables over time. However, the sample data in this article are complete in terms of regional dimensions (51 states in the USA), which can well reflect the differences between regions. So, this article uses an individual-specific effects panel regression model.

Firstly, we begin with a conceptual model by considering the epidemiological vulnerability $(E V I)$ as the outcome of two input variables, GDP growth ( $d G D P)$ and the percentage of urban population $(P U)$. Then the access to health services $(A S I)$ and population characters $(P C I)$ are added as control variables as they affect vulnerability in terms of medical treatment and healthcare resources and disease susceptivity by population size, respectively (Vlahov and Galea 2002). Therefore:

$$
E V I=f(d G D P, P U, A S I, P C I)
$$

Secondly, we construct EVI by adding the prevalence of HIV, smoking, diabetes, obesity, and hypertension. Then, we select the real GDP growth per capita to represent economic growth $(d G D P)$, urban population percentage as urbanization $(P U)$ index, hospital bed rate (HosBed) and active physicians (ActPhy) as public access to public services (ASI) index, and population density (PopDensity) and elderly people (Elderly) to present population characteristics $(P C I)$ index. In such case, the regression model is Eq. (2),

$$
\mathbf{E V I}_{i, t}=\mathrm{Bx}_{i, t}+\lambda_{i}+\varepsilon_{i, t}
$$

where $i$ stands for $i$ th district and $t$ stands for a certain year, $\varepsilon_{i, t}$ is a vector with white noise sequences components, $\lambda_{i}$ is the residual term of district-fixed effect, the dependent variable EVI $\mathbf{I}_{i, t}=\left(\ln \left(H I V_{i, t}\right), \ln \left(\text { Smok }_{i, t}\right), \ln \left(\text { Diab }_{i, t}\right), \ln \left(\text { Obsity }_{i, t}\right), \ln \left(\text { Hyper }_{i, t}\right)\right)^{T}$,

the independent variable $\mathbf{x}_{i, t}=\left(1, \Delta \ln \left(\operatorname{RealGDP}_{i, t}\right), \ln \left(\operatorname{Pop}_{i, t}\right), \ln \left(\operatorname{HosBed}_{i, t}\right)\right.$, $\ln \left(\right.$ ActPhy $\left._{i, t}\right), \ln \left(\right.$ Elderly $\left.\left._{i, t}\right)\right)^{T}$, where Pop $_{i, t}=$ UrbanPop $_{i, t}$ or PopDensity Pr,t $_{\text {and, }}$, $\Delta \ln \left(\right.$ RealGDP $\left._{i, t}\right)=\ln \left(\right.$ RealGDP $\left._{i, t}\right)-\ln \left(\right.$ RealGDP $\left._{i, t-1}\right)$ the coefficient matrix $\mathrm{B}=\left(\beta_{k, j}\right)_{1 \leq k \leq 5,0 \leq j \leq 4}$, and $e v i_{i, t}$ is used in place of $E V I_{i, t}$ in Eq. (2) to estimate the impact of economic growth on epidemiological vulnerability. Equation (2) can be further specified as:

$$
\begin{aligned}
\text { evi }_{i, t}= & \beta_{0}+\beta_{1} \Delta \ln \left(\text { RealGDP }_{i, t}\right)+\beta_{2} \ln \left(\text { Pop }_{i, t}\right)+\beta_{3} \ln \left(\text { HosBed }_{i, t}\right) \\
& +\beta_{4} \ln \left(\text { ActPhy }_{i, t}\right)+\beta_{5} \ln \left(\text { Elderly }_{i, t}\right)+\lambda_{i}+\varepsilon_{i, t}
\end{aligned}
$$

where $e v i_{i, t}$ is the equal-weighted natural logarithm sum of the five subitems:

$$
e v i_{i, t}=\ln \left(H I V_{i, t}\right)+\ln \left(\text { Smok }_{i, t}\right)+\ln \left(\text { Diab }_{i, t}\right)+\ln \left(\text { Obsity }_{i, t}\right)+\ln \left(\text { Hyper }_{i, t}\right)
$$

The regression parameters are estimated by ordinary least squares. Coefficient $\beta_{i}$ stands for correlation between dependent variables and independent variables; that is to say, a positive regression parameter $\beta_{1}$ reflects a positive relationship between economic growth and vulnerability. We also replace the $e v i_{i, t}$ in Eq. (3) with its subitems from Eq. (3.1) and with CDC SVI, respectively, to evaluate the impact of 
economic changes on each specific epidemiological vulnerability indicator and the comprehensive social vulnerability indicator.

Thirdly, we apply the model to the ongoing COVID-19 pandemic by altering the outcome variable in Eq. (2) with COVID-19 incidents and mortality rate to test if the "economy-health" relationship remains the same:

$$
\begin{aligned}
& \ln \left(\text { Covid Case }_{i}(k)\right)=\beta_{0}+\beta_{1} \Delta \ln (\text { Real GDP })+\beta_{2} \ln \left(\text { Pop }_{i}\right)+\beta_{3} \ln \left(\text { HosBed }_{i}\right) \\
& +\beta_{4} \ln (\text { Act Phy } i)+\beta_{5} \ln \left(\text { Elderly }_{i}\right)+\varepsilon_{i} \\
& \ln \left(\text { Covid Death }_{i}(k)\right)=\beta_{0}+\beta_{1} \Delta \ln \left(\text { RealGDP }_{i}\right)+\beta_{2} \ln \left(\text { Pop }_{i}\right)+\beta_{3} \ln \left(\text { HosBed }_{i}\right) \\
& +\beta_{4} \ln \left(\text { ActPhy }_{i}\right)+\beta_{5} \ln \left(\text { Elderly }_{i}\right)+\varepsilon_{i}
\end{aligned}
$$

where CovidCase $_{i}(k)$ stands for COVID-19 case rate in the $i$ th state in the USA on the $k$ th day, CovidDeath $(k)$ as COVID-19 mortality rate correspondingly, while independent variables remain unchanged. Notably, the model in Eq. (2) with EVI presents the long-term health effect of economic development, while the model in Eq. (4) and (5) treats COVID-19 as a public health emergency to examine the relationship between economic activities and COVID-19 outbreak.

\subsection{Variables}

\subsubsection{Dependent variable}

Epidemiological Vulnerability Index (EVI) The epidemiological profile is a critical indicator of community vulnerability because individuals with preexisting medical conditions/diseases or unhealthy lifestyles have higher risks of developing diseases and poorer prognosis (Rezende et al. 2020). In this study, EVI is the natural logarithmic sum of five well-studied and widely accepted prevalence indicators (i.e., HIV, diabetes, hypertension, smoking, and obesity). HIV is an infectious virus that could cause acquired immunodeficiency syndrome if not treated, and the infected people have severer prognoses and a higher mortality rate from opportunistic infections (Benson et al. 2009). Diabetes, hypertension, smoking, and obesity are the top risk factors of chronic diseases, and cardiovascular/heart issues remain the leading causes of morbidity and mortality for years (Basu et al. 2019; Shah et al. 2019). The definitions for each variable in selected datasets are the number of $>13$-year-old residence at diagnosis of HIV per 100,000, the percentage of current smoking adults and hypertension among adults (US CDC, https://www.cdc.gov/), and the percentage of diagnosed diabetes among adults (State of Childhood Obesity, https://state ofchildhoodobesity.org/).

Social Vulnerability Index (SVI) CDC SVI is defined as a social condition or a measure of population groups' vulnerability when confronted by a disaster or other stressors. In this study, we use CDC SVI in place of EVI to validate the public health effects caused by economic development as SVI highly correlated well with health 
outcomes (Khazanchi et al. 2020; Stanturf et al. 2015). The CDC SVI is calculated from 15 items to describe the vulnerability from socioeconomic status, household composition, disability, minority status, language, housing, and transportation. Each item's value is the percentile rank of the census tract and therefore is on a scale from 0 to 1 . To match the study's overall resolution of the data, we average the census track SVI as the state's score for each year of study (US CDC, https://www.atsdr. cdc.gov/placeandhealth/svi/).

COVID-19 Incident Rate and Death Rate We take verified COVID-19 data to examine if economic growth or urbanization's effect on the current pandemic is consistent with EVI and SVI. The accumulative case and death data are from January 21, 2020, to the last days of the three months that have the highest case spikes (The COVID Tracking Project at The Atlantic, https://covidtracking.com/). The numbers are divided by population data from US Census Bureau to calculate the rates.

\subsubsection{Independent variable}

GDP Growth Per Capita is an inflation-adjusted measure of each state's gross product based on national prices for the goods and services produced within the state. GDP is divided by the state's total population to get GDP per capita (https://www. bea.gov/). Percentage of Urban Population is the percentage of the urban population against the state's total population and is used to describe the urbanization level of the area. Population Density is the average population per square mile and is expected to increase the vulnerability indexes as well as COVID-19 spread. As population density increases, the transmission rate of infectious diseases arises, together with other issues, including informal settlements, homeless and insufficient basic facilities (Macharia et al. 2020). The Elderly is defined as the percentage of the population that is over 65 years old. All data are available on US Census Bureau (https://www.census.gov/). Hospital Beds per 1,000 has been used to represent the general distribution of healthcare supplies in the USA (http://ghdx.healthdata.org/). Active Physician is defined as physicians (federal and nonfederal) licensed by a state per 100,000 population, provided they are working at least $20 \mathrm{~h}$ per week (https:// www.aamc.org/). We used this variable to adjust the effect of economic growth on healthcare resource distribution.

\subsection{Descriptive statistics}

Table 1 provides a descriptive summary of each variable. The variable correlations are displayed in Fig. 1, including distribution, correlation coefficient, significant level, and paired scatter plots. No obvious collinearity exists among the variables; all the variables are normally distributed without obvious outliners.

Figure 2 visualizes the geographic trends of EVI, SVI, GDP growth per capita, COVID-19 incidence, and mortality, respectively. The darker gray indicates the region is more susceptible to disastrous hazards and diseases, has more people affected by COVID-19, or has a higher economic growth rate. EVI and SVI have similar patterns: lighter color (less vulnerable) in Montana, Wyoming, North 


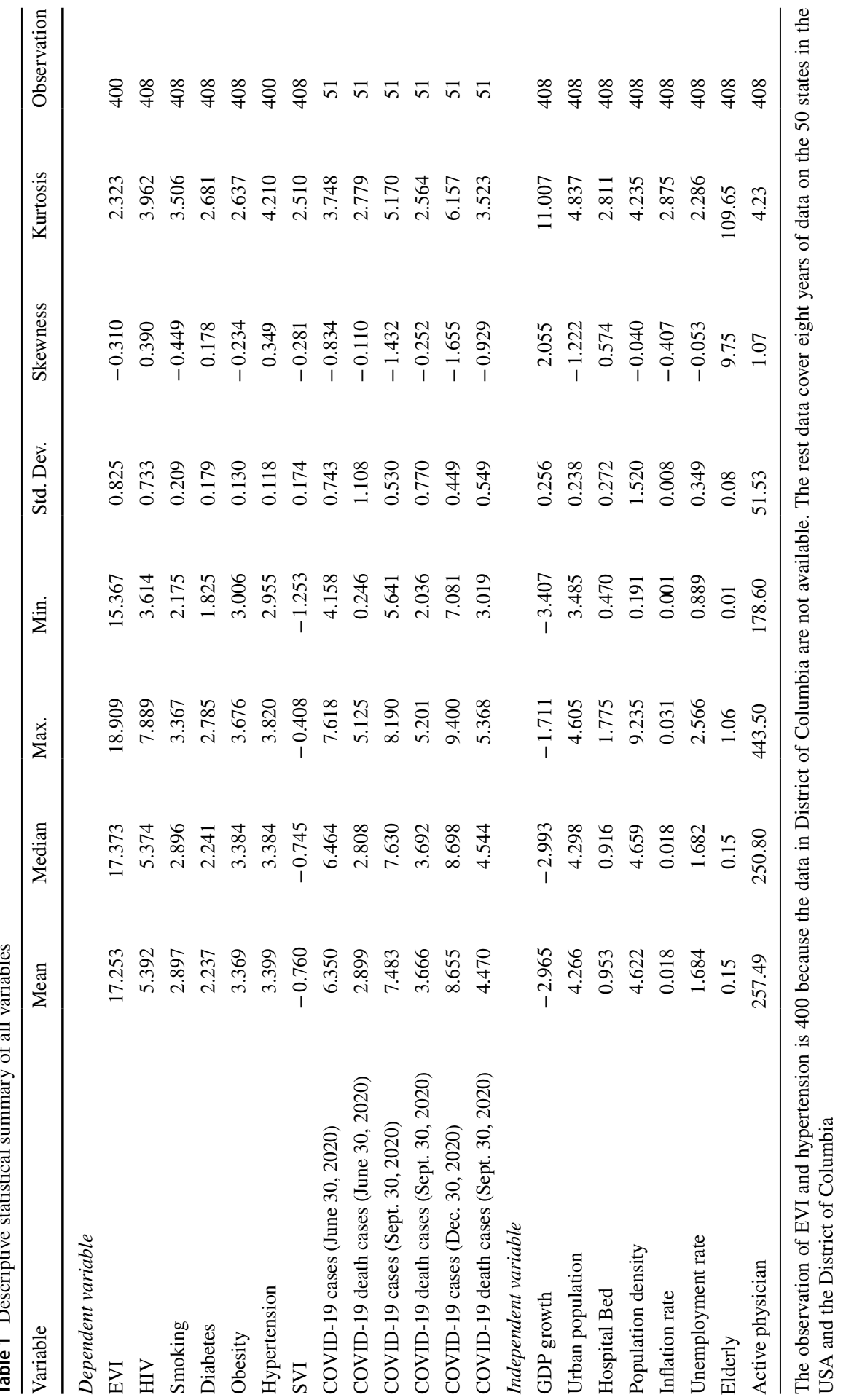




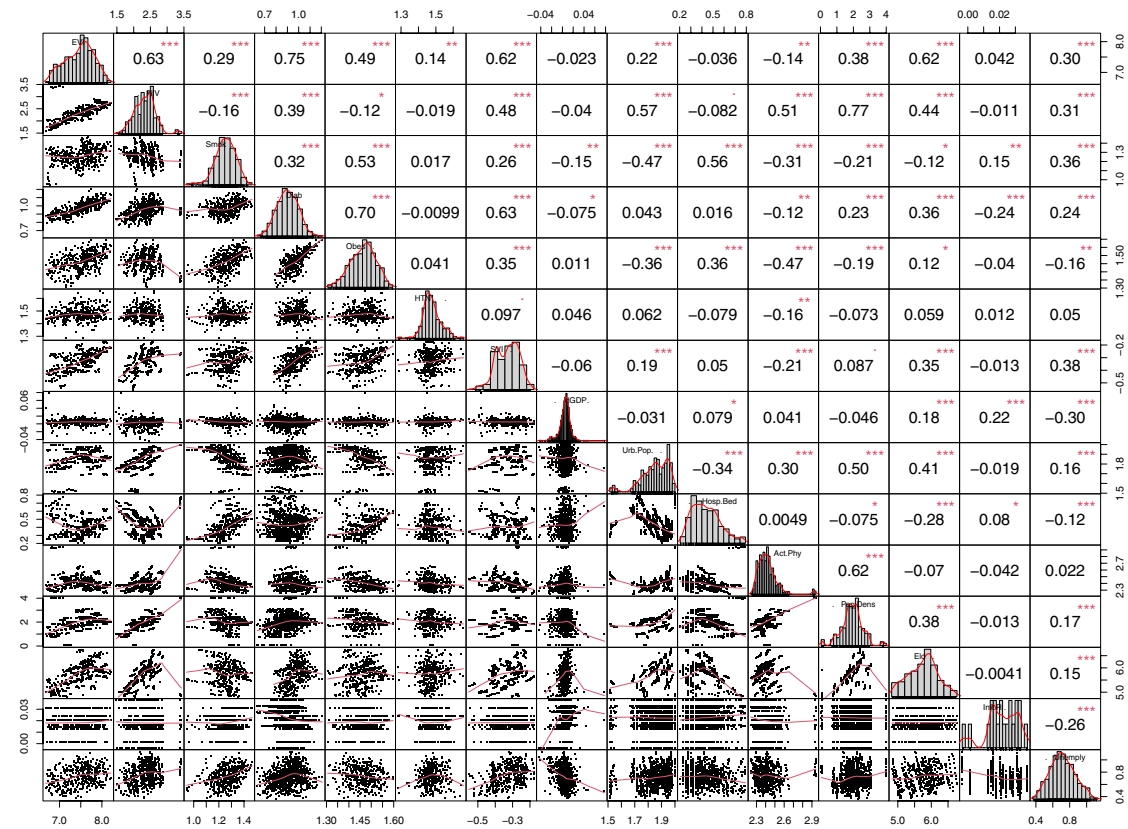

Note: Significance level cut points are $<0.001(* *), 0.01(* *), 0.05(*), 0.1($.$) . Variables from top left to bottom right are EVI, the prevalence of$ HIV, smoking, diabetes, obesity, and hypertension among adults, SVI, GDP growth per capita, percentage of the urban population, hospital beds per 1,000 , population density, inflation rate, and unemployment rate, respectively.

Fig. 1 Correlation matrix between each pair of variables

Dakota, South Dakota, Minnesota, and Iowa (rocky mountain region and mid-west region); darker color (more vulnerable) in the south and west coast. The pattern for GDP growth per capita looks the opposite: mid-west regions experienced higher growth rates than the south, specifically Montana, North Dakota, South Dakota, Nebraska, and Iowa. The two maps for COVID-19 distribution looked the same between incidence and mortality, with the south region relatively darker (especially Nevada, New Mexico, Arkansas, Alabama, and North Carolina) than the north and mid-west.

\section{Empirical results}

\subsection{The results for the two vulnerability models and the COVID-19 models}

The multiple panel regression models on the effects of economic activities on the two vulnerability indexes are shown in Table 2. This part's overall finding is that GDP growth per capita is negatively related to EVI; the correlation coefficient is -0.813 (standard error $=0.473, p<0.1$ ), indicating economic growth is associated with a lower disease burden statewide. On the contrary, per unit of urban population 
(a) Epidemiologcial Vulnerability Index

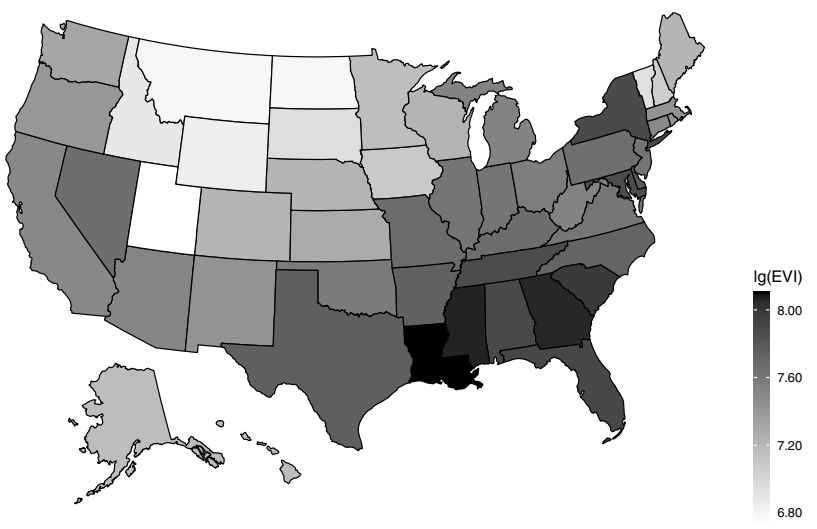

(b) Social Vulnerability Index

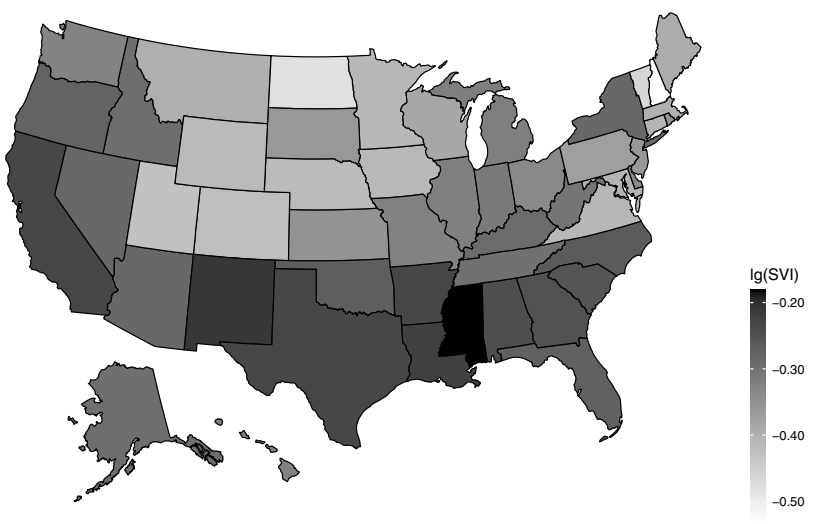

(c) GDP Growth per Capita

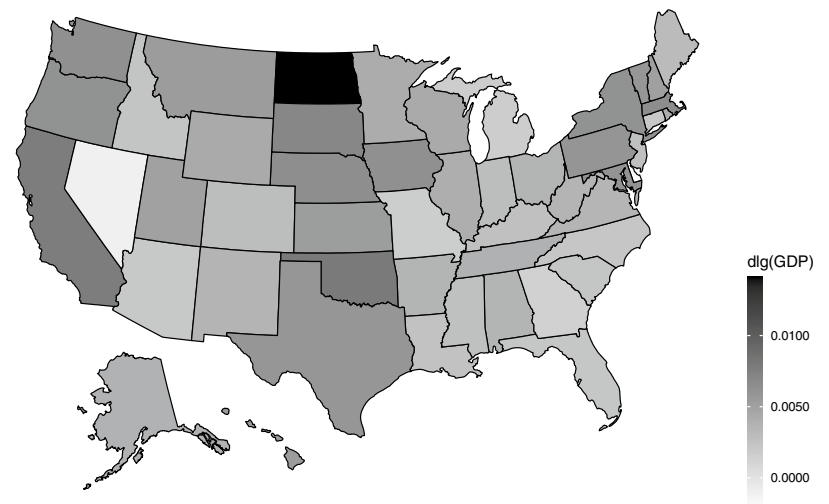

Fig. 2 Distribution of major variables. Source: Author's calculation 
(d) COVID-19 Incident Rate (per 100,000)

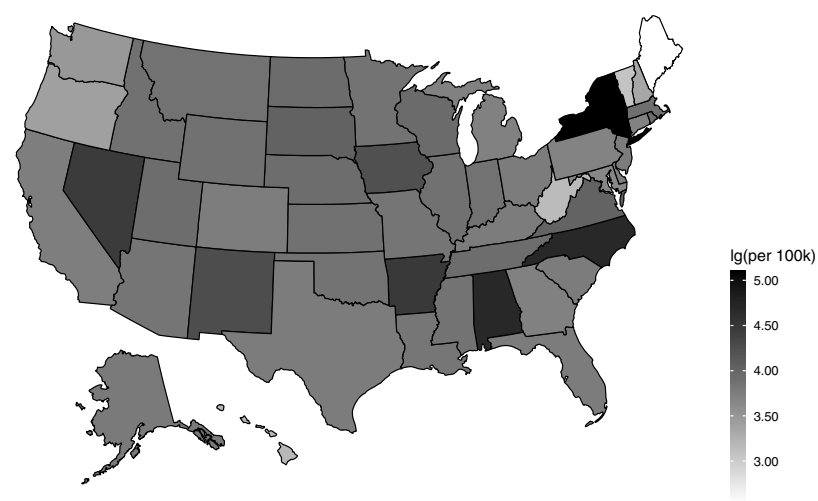

(e) COVID-19 Death Rate (per 100,000)

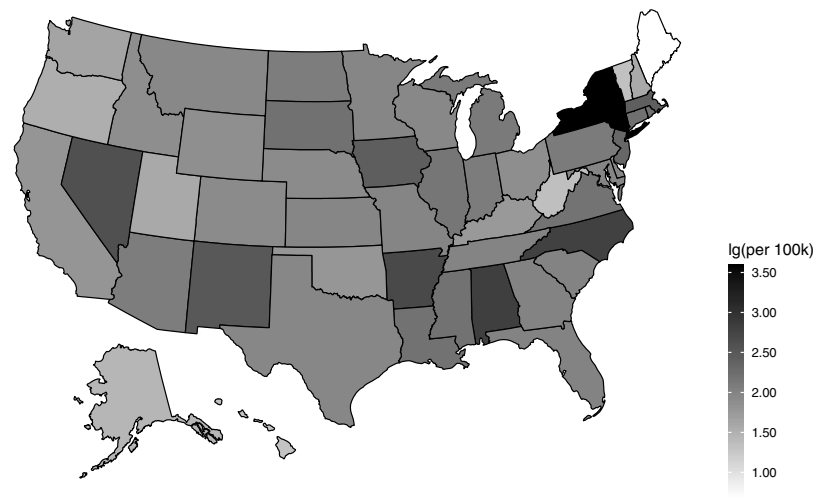

Fig. 2 (continued)

density (agglomeration) increases EVI by 4.347 (standard error $=1.318, p<0.01$ ), indicating that urban population capital concentration potentially deteriorates the overall health condition during economic development. Population density increases EVI by 2.15 (standard error $=0.466, p<0.01$ ). By digging into EVI subcategories, an increase in per capita income is significantly associated with a lower HIV rate. Urban population agglomeration has a positive relationship with the smoking rate but negative relationships with obesity. This finding is consistent with Laaksonen et al. (2005) that smoking behavior is associated with socioeconomic disadvantages during urbanization. The 2001-2016 National Health and Nutrition Examination Surveys (NHNES) also support our finding that severe obesity is inversely associated with the US urbanization level (Ogden et al. 2018).

The higher EVI is associated with the increases in the two control variables of hospital beds and active physicians, but no significant relationship with the elderly. The densely populated area is usually related with environmental pollution, heat 
Table 2 Panel regression results for the main variables

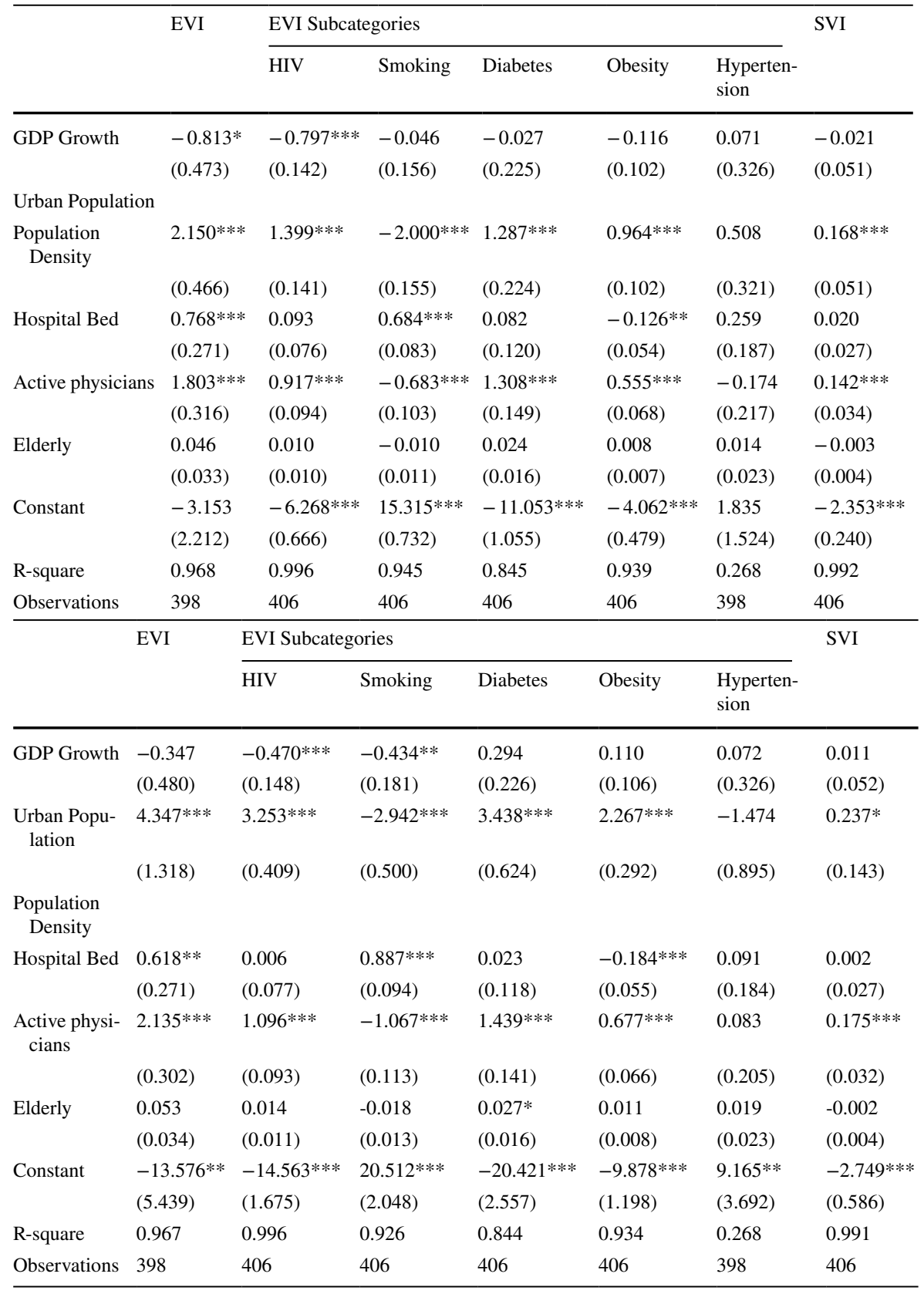

$*, * *$, and $* * *$ indicate that the regression coefficient is significant at the significance level of $0.1,0.05$, and 0.01 , respectively. Cluster-robust standard errors are in parentheses 
stress, crowded housing, and larger disparities in income, food quality, and access to health care (Liddle 2017), which could explains its association with the higher vulnerability on health because more hospital resources are needed for a more vulnerable society. Comparing the regression results of SVI with EVI, we find similar trends that population density and active physicians are significantly associated with higher social vulnerability levels. However, no strong relationship is found between SVI and GDP growth or population elderly rate.

Different from EVI and SVI, which present the long-term public health condition, we use COVID-19 pandemic data to test the effect of economic activities on the vulnerability to the public health crisis. The result is presented in Table 3 . The empirical result shows GDP growth has no significant impact on the COVID-19 case/death rate on any of the three time points. But the urban population and population density are positively correlated with the COVID-19 case and death rate in most of the dates. Urbanization and population density are the dominant factors on the severity of the pandemic status in the USA compared to economic development, which is in line with the essence of infectious diseases. The positive relationship between hospital bed and COVID-19 data is, again, complicated to explain as it cannot be determined by our model and requires further research. However, it suggests a dynamic medical resource relocation progress during the pandemic from the correlation coefficient as time goes.

\subsection{Robustness checks}

In this part, we test our model by replacing GDP growth rate with the unemployment rate as the independent variable:

$$
\begin{aligned}
\text { EVI }_{i, t}(k)= & \beta_{0}+\beta_{1} \text { UnempRate }_{i, t}+\beta_{2} \ln \left(\text { Pop }_{i, t}\right)+\beta_{3} \ln \left(\text { HosBed }_{i, t}\right) \\
& +\beta_{4} \ln \left(\text { ActPhy }_{i, t}\right)+\beta_{5} \ln \left(\text { Elderly }_{i, t}\right)+\lambda_{i}+\varepsilon_{i, t}
\end{aligned}
$$

where Unemp Rate stands for unemployment rate in ith state of the USA and $t$ stands for the corresponding year. Topic connecting unemployment with health is well discussed in previous literature that unemployment and economic growth are indicators of inverse causality (Soylu et al. 2018). In our result, the correlation coefficient between unemployment and EVI is insignificant. In addition, the urban population and population density rate increase EVI significantly which shows population characteristic has a positive impact on social health vulnerability. The results also suggest that one percent increase in the unemployment rate number of leads to $2.7 \%$ increase in smoking prevalence (standard error $=0.003, p<0.01$ ), and the diabetes rate would decrease $1.1 \%$ (standard error $=0.005, p<0.05$ ). R-square for both models is above 0.60 , which shows a good fitting effect. Despite the changes displayed above, hospital beds and active physicians exhibit the same effect as the main model after replacing GDP growth per capita with the unemployment index (Table 4). 
Table 3 Regression results for economic growth on COVID-19

\begin{tabular}{|c|c|c|c|c|c|c|}
\hline & \multicolumn{2}{|c|}{ Jan 21, 2020-Jun 30, 2020} & \multicolumn{2}{|c|}{$\begin{array}{l}\text { Jan } 21,2020-\text { Sept } 30 \\
2020\end{array}$} & \multicolumn{2}{|c|}{$\begin{array}{l}\text { Jan 21, 2020-Dec 31, } \\
2020\end{array}$} \\
\hline & Incident Rate & Death Rate & Incident Rate & Death Rate & Incident Rate & Death Rate \\
\hline GDP Growth & $\begin{array}{l}0.082 \\
(0.314)\end{array}$ & $\begin{array}{l}0.191 \\
(0.445)\end{array}$ & $\begin{array}{l}-0.001 \\
(0.199)\end{array}$ & $\begin{array}{l}-0.089 \\
(0.298)\end{array}$ & $\begin{array}{l}-0.037 \\
(0.186)\end{array}$ & $\begin{array}{l}0.073 \\
(0.252)\end{array}$ \\
\hline \multicolumn{7}{|l|}{ Urban Population } \\
\hline $\begin{array}{l}\text { Population } \\
\text { Density }\end{array}$ & $\begin{array}{l}0.383 * * * \\
(0.075)\end{array}$ & $0.541 * * *$ & $0.241 * * *$ & $0.450 * * *$ & $\begin{array}{l}0.049 \\
(0.045)\end{array}$ & $\begin{array}{l}0.218 * * * \\
(0.060)\end{array}$ \\
\hline Hospital Bed & $\begin{array}{l}0.403 \\
(0.319)\end{array}$ & $\begin{array}{l}0.336 \\
(0.451)\end{array}$ & $\begin{array}{l}0.613 * * * \\
(0.202)\end{array}$ & $\begin{array}{l}0.458 \\
(0.302)\end{array}$ & $\begin{array}{l}0.666^{* * *} \\
(0.189)\end{array}$ & $\begin{array}{l}0.910 * * * \\
(0.256)\end{array}$ \\
\hline Active physicians & $\begin{array}{l}-0.857 \\
(0.529)\end{array}$ & $\begin{array}{l}-0.257 \\
(0.749)\end{array}$ & $\begin{array}{l}-1.523 * * * \\
(0.336)\end{array}$ & $\begin{array}{l}-0.929 * \\
(0.502)\end{array}$ & $\begin{array}{l}-0.952 * * * \\
(0.314)\end{array}$ & $\begin{array}{l}-0.862 * * \\
(0.425)\end{array}$ \\
\hline elderly & $\begin{array}{l}-1.413^{*} \\
(0.796)\end{array}$ & $\begin{array}{l}-0.197 \\
(1.127)\end{array}$ & $\begin{array}{l}-1.761^{* * *} \\
-0.505\end{array}$ & $\begin{array}{l}-0.764 \\
(0.755)\end{array}$ & $\begin{array}{l}-1.295^{* * * *} \\
(0.472)\end{array}$ & $\begin{array}{l}-0.211 \\
(0.639)\end{array}$ \\
\hline Constant & $\begin{array}{l}6.435^{*} \\
(3.487)\end{array}$ & $\begin{array}{l}1.151 \\
(4.938)\end{array}$ & $\begin{array}{l}11.133 * * * \\
(2.211)\end{array}$ & $\begin{array}{l}4.966 \\
(3.307)\end{array}$ & $\begin{array}{l}10.798 * * * \\
(2.067)\end{array}$ & $\begin{array}{l}7.061 * * \\
(2.799)\end{array}$ \\
\hline R-square & 0.451 & 0.507 & 0.558 & 0.540 & 0.469 & 0.355 \\
\hline \multirow[t]{3}{*}{ Observations } & 50 & 50 & 50 & 50 & 50 & 50 \\
\hline & \multicolumn{2}{|c|}{ Jan 21, 2020-Jun 30, 2020} & \multicolumn{2}{|c|}{$\begin{array}{l}\text { Jan 21, 2020-Sept 30, } \\
2020\end{array}$} & \multicolumn{2}{|c|}{$\begin{array}{l}\text { Jan 21, 2020-Dec 31, } \\
2020\end{array}$} \\
\hline & Incident Rate & Death Rate & Incident Rate & Death Rate & Incident Rate & Death Rate \\
\hline GDP Growth & $\begin{array}{l}-0.221 \\
(0.333)\end{array}$ & $\begin{array}{l}-0.267 \\
(0.489)\end{array}$ & $\begin{array}{l}-0.140 \\
(0.165)\end{array}$ & $\begin{array}{l}-0.433 \\
(0.321)\end{array}$ & $\begin{array}{l}-0.008 \\
(0.152)\end{array}$ & $\begin{array}{l}-0.044 \\
(0.219)\end{array}$ \\
\hline Urban Population & $\begin{array}{l}1.679 * * * \\
(0.454)\end{array}$ & $\begin{array}{l}2.083 * * * \\
(0.666)\end{array}$ & $\begin{array}{l}1.596 * * * \\
(0.225)\end{array}$ & $\begin{array}{l}2.104 * * * \\
(0.437)\end{array}$ & $\begin{array}{l}0.912 * * * \\
(0.207)\end{array}$ & $\begin{array}{l}1.536^{* * * *} \\
(0.298)\end{array}$ \\
\hline \multicolumn{7}{|l|}{$\begin{array}{c}\text { Population } \\
\text { Density }\end{array}$} \\
\hline Hospital Bed & $\begin{array}{l}0.729 * \\
(0.369)\end{array}$ & $\begin{array}{l}0.722 \\
(0.540)\end{array}$ & $\begin{array}{l}0.955^{* * * *} \\
(0.182)\end{array}$ & $\begin{array}{l}0.874 * * \\
(0.355)\end{array}$ & $\begin{array}{l}0.886^{* * * *} \\
(0.168)\end{array}$ & $\begin{array}{l}1.244 * * * \\
(0.242)\end{array}$ \\
\hline Active physicians & $\begin{array}{l}0.534 \\
(0.443)\end{array}$ & $\begin{array}{l}1.787 * * * \\
(0.649)\end{array}$ & $\begin{array}{l}-0.786^{* * *} \\
(0.219)\end{array}$ & $\begin{array}{l}0.675 \\
(0.426)\end{array}$ & $\begin{array}{l}-0.956^{* * * *} \\
(0.201)\end{array}$ & $\begin{array}{l}-0.219 \\
(0.290)\end{array}$ \\
\hline elderly & $\begin{array}{l}-0.438 \\
(0.949)\end{array}$ & $\begin{array}{l}0.937 \\
(1.392)\end{array}$ & $\begin{array}{l}-0.699 \\
(0.469)\end{array}$ & $\begin{array}{l}0.489 \\
(0.914)\end{array}$ & $\begin{array}{l}-0.589 \\
(0.432)\end{array}$ & $\begin{array}{l}0.827 \\
(0.623)\end{array}$ \\
\hline Constant & $\begin{array}{l}-5.300 \\
(3.359)\end{array}$ & $\begin{array}{l}-15.005^{* * *} \\
(4.925)\end{array}$ & $\begin{array}{l}2.903 * \\
(1.661)\end{array}$ & $\begin{array}{l}-9.043^{* * * *} \\
(3.233)\end{array}$ & $\begin{array}{l}8.219 * * * \\
(1.527)\end{array}$ & $\begin{array}{l}-0.525 \\
(2.203)\end{array}$ \\
\hline R-square & 0.335 & 0.360 & 0.675 & 0.427 & 0.622 & 0.479 \\
\hline Observations & 50 & 50 & 50 & 50 & 50 & 50 \\
\hline
\end{tabular}

$*, * *$, and $* * *$ indicate that the regression coefficient is significant at the significance level of $0.1,0.05$, and 0.01 , respectively. Cluster-robust standard errors are in parentheses 
Table 4 Robustness check with the unemployment rate

\begin{tabular}{|c|c|c|c|c|c|c|c|}
\hline & \multirow[t]{2}{*}{ EVI } & \multicolumn{5}{|c|}{ EVI Subcategories } & \multirow[t]{2}{*}{ SVI } \\
\hline & & HIV & Smoking & Diabetes & Obesity & $\begin{array}{l}\text { Hyperten- } \\
\text { sion }\end{array}$ & \\
\hline \multirow{2}{*}{$\begin{array}{l}\text { Unemploy- } \\
\text { ment Rate }\end{array}$} & 0.013 & -0.005 & $0.027 * * *$ & $-0.011 * *$ & -0.004 & 0.009 & $0.004 * * *$ \\
\hline & $(0.010)$ & $(0.003)$ & $(0.003)$ & $(0.005)$ & $(0.002)$ & $(0.007)$ & $(0.001)$ \\
\hline \multicolumn{8}{|l|}{$\begin{array}{l}\text { Urban } \\
\text { Population }\end{array}$} \\
\hline \multirow{2}{*}{$\begin{array}{l}\text { Population } \\
\text { Density }\end{array}$} & $2.562 * * *$ & $1.108 * * *$ & $-0.923 * * *$ & $0.830 * * *$ & $0.805 * * *$ & $0.885^{* *}$ & $0.322 * * *$ \\
\hline & $(0.623)$ & $(0.196)$ & $(0.187)$ & $(0.295)$ & $(0.135)$ & $(0.427)$ & $(0.066)$ \\
\hline \multirow{2}{*}{$\begin{array}{l}\text { Hospital } \\
\text { Bed }\end{array}$} & $0.625 * *$ & 0.089 & $0.486^{* * *}$ & 0.162 & $-0.105^{*}$ & 0.205 & -0.010 \\
\hline & $(0.278)$ & $(0.082)$ & $(0.078)$ & $(0.124)$ & $(0.056)$ & $(0.191)$ & $(0.028)$ \\
\hline \multirow{2}{*}{$\begin{array}{l}\text { Active phy- } \\
\text { sicians }\end{array}$} & $1.953 * * *$ & $0.775 * * *$ & $-0.232 * *$ & $1.116^{* * *}$ & $0.486 * * *$ & -0.008 & $0.206^{* * *}$ \\
\hline & $(0.362)$ & $(0.112)$ & $(0.107)$ & $(0.169)$ & $(0.077)$ & $(0.248)$ & $(0.038)$ \\
\hline \multirow[t]{2}{*}{ Elderly } & 0.048 & 0.010 & -0.007 & 0.022 & 0.008 & 0.016 & -0.002 \\
\hline & $(0.033)$ & $(0.011)$ & $(0.010)$ & $(0.016)$ & $(0.007)$ & $(0.023)$ & $(0.004)$ \\
\hline \multirow[t]{2}{*}{ Constant } & -5.799 & $-4.105^{* * *}$ & $7.844 * * *$ & $-7.880^{* * *}$ & $-2.937 * * *$ & -0.797 & $-3.421 * * *$ \\
\hline & $(3.601)$ & (1.129) & (1.082) & $(1.706)$ & (0.779) & $(2.470)$ & $(0.384)$ \\
\hline $\mathrm{R}$-square & 0.968 & 0.996 & 0.955 & 0.847 & 0.939 & 0.271 & 0.992 \\
\hline \multirow{3}{*}{$\begin{array}{l}\text { Observa- } \\
\text { tions }\end{array}$} & 398 & 406 & 406 & 406 & 406 & 398 & 406 \\
\hline & EVI & EVI Subcate & egories & & & & $\mathrm{SVI}^{\mathrm{a}}$ \\
\hline & & HIV & Smoking & Diabetes & Obesity & $\begin{array}{l}\text { Hyperten- } \\
\text { sion }\end{array}$ & \\
\hline \multirow{2}{*}{$\begin{array}{l}\text { Unemploy- } \\
\text { ment Rate }\end{array}$} & -0.006 & $-0.011 * * *$ & $0.035^{* * *}$ & $-0.015^{* * *}$ & $-0.009^{* * *}$ & 0.005 & 0.001 \\
\hline & $(0.008)$ & $(0.003)$ & $(0.003)$ & $(0.004)$ & $(0.002)$ & $(0.006)$ & $(0.001)$ \\
\hline \multirow{2}{*}{$\begin{array}{l}\text { Urban Popu- } \\
\text { lation }\end{array}$} & $4.047 * * *$ & $2.734 * * *$ & -0.526 & $2.384 * * *$ & $1.680 * * *$ & $-1.807^{*}$ & $0.296 *$ \\
\hline & (1.417) & $(0.433)$ & $(0.432)$ & $(0.656)$ & $(0.303)$ & $(0.961)$ & $(0.153)$ \\
\hline \multicolumn{8}{|l|}{$\begin{array}{c}\text { Population } \\
\text { Density }\end{array}$} \\
\hline \multirow{2}{*}{$\begin{array}{l}\text { Hospital } \\
\text { Bed }\end{array}$} & $0.669 * *$ & 0.120 & $0.489 * * *$ & 0.191 & -0.088 & 0.141 & -0.009 \\
\hline & $(0.283)$ & $(0.081)$ & $(0.081)$ & $(0.123)$ & $(0.057)$ & $(0.192)$ & $(0.029)$ \\
\hline \multirow{2}{*}{$\begin{array}{l}\text { Active phy- } \\
\text { sicians }\end{array}$} & $1.917 * * *$ & $0.755^{* * * *}$ & $-0.220 * *$ & $1.100 * * *$ & $0.472 * * *$ & -0.030 & $0.202 * * *$ \\
\hline & $(0.366)$ & $(0.111)$ & $(0.110)$ & $(0.167)$ & $(0.077)$ & $(0.248)$ & $(0.039)$ \\
\hline \multirow[t]{2}{*}{ Elderly } & 0.051 & 0.011 & -0.008 & 0.023 & 0.008 & 0.017 & -0.002 \\
\hline & $(0.034)$ & $(0.010)$ & $(0.010)$ & $(0.016)$ & $(0.007)$ & $(0.023)$ & $(0.004)$ \\
\hline \multirow[t]{2}{*}{ Constant } & $-11.109 *$ & $-10.509 * * *$ & $5.683 * * *$ & $-14.113 * * *$ & $-6.279 * * *$ & $11.192 * *$ & $-3.148 * * *$ \\
\hline & $(6.458)$ & $(1.955)$ & $(1.952)$ & $(2.961)$ & $(1.371)$ & $(4.380)$ & $(0.690)$ \\
\hline
\end{tabular}


Table 4 (continued)

\begin{tabular}{|c|c|c|c|c|c|c|c|}
\hline & \multirow[t]{2}{*}{ EVI } & \multicolumn{5}{|c|}{ EVI Subcategories } & \multirow[t]{2}{*}{$\mathrm{SVI}^{\mathrm{a}}$} \\
\hline & & HIV & Smoking & Diabetes & Obesity & $\begin{array}{l}\text { Hyperten- } \\
\text { sion }\end{array}$ & \\
\hline R-square & 0.967 & 0.996 & 0.952 & 0.849 & 0.938 & 0.270 & 0.991 \\
\hline $\begin{array}{l}\text { Observa- } \\
\text { tions }\end{array}$ & 398 & 406 & 406 & 406 & 406 & 398 & 406 \\
\hline
\end{tabular}

\section{Conclusions}

In this paper, we first review the articles on the public health effect of economic development, among which we conclude health indicators such as life expectancy, infant mortality, and disease mortality rate are used as major measurements of health outcomes. We summarized the major findings and proposed our hypothesis from a vulnerability perspective that: (1) economic growth leads to lower vulnerability of health; and (2) urbanization increases health vulnerability. To explain the mechanism of this two-sided health effect of economic development, we construct the epidemiological vulnerability index as a dependent variable, and then we use GDP growth rate, urban population, access to health service (hospital beds and active physicians) and population characteristics (density and elderly population) in the model as explanatory variables. EVI's model fitness is then compared with CDC social vulnerability index (SVI) and COVID-19 data, as EVI includes the preexisting medical conditions and behavioral risk factors, SVI represents potential socioeconomic risk factors for adverse health outcomes, and COVID-19 pandemic represents our model application in a public health crisis. The major findings are: (1) economic growth has a moderately positive effect on lowering the epidemiological vulnerability; (2) urbanization is significantly associated with higher epidemiological vulnerability, especially to highly infectious diseases such as COVID-19. Our results prioritize the need to mitigate health risks brought by urbanization and highlight the importance of including multiple health indicators in economic health studies.

An economically advanced community is less vulnerable to diseases and thus more resilient to health stressors, which is reasonable. However, the positive relationship between urbanization with EVI and SVI indicates a higher risk of developing illnesses and more significant disease burdens, specifically communicable diseases. In the rapid urbanized area, physical environment changes, crowded housing, and air pollution reduced outdoor activities. The high cost of the living, competitive job market, fast-paced lifestyle, and peer pressure contribute to higher risks of smoking, alcohol, and drug abuse. All the factors expose city dwellers to higher risks of injuries, cancer, cardiovascular diseases, and mental health issues. What is 
more, densely populated urban area means a higher chance of exposure to infectious disease, which is well proved by our HIV and COVID-19 data. More frequent human activities contribute to the disease spread. Exacerbated inequity also means it is hard to distribute medical sources equally to the people in need, and it becomes the weakest point of a community's safety net against infectious diseases. Our next step is to include disparity in our model to explore how it may alter the economic effect on social vulnerability.

This paper's results may be relevant for economic policymakers, especially for the fields of rational allocation of economic resources for health management and disease control. Firstly, urban health status is in constant change, traditional public health indicators (i.e., death rate, life expectancy) cannot reflect real-time public health conditions. Authorities and agencies need to add health vulnerability indicators to make more beneficial policies. Secondly, the positive effect of economic growth is undeniable, but from the vulnerability aspect (especially the epidemiological vulnerability), the economic growth has brought more pressure on public health by urban agglomeration, the speed of which outruns the health resources it creates, whereas population agglomeration paves the foundation of urban development. Thirdly, the misallocation of public resources accounts for most of the urban vulnerability, the development issue of which should not be buried under the macro-economic numbers. The COVID-19 pandemic revealed the classic wooden barrel theory: economic development ceases or gets dragged to recession once public health goes wrong. Lastly, using the multi-dimensional vulnerability index, building a dynamic health surveillance-response system, and efficiently distributing public health resources will play a long-lasting and sustainable effect on healthy economic development.

Supplementary Information The online version contains supplementary material available at https://doi. org/10.1007/s00168-021-01103-9.

\section{References}

Anand S, Ravallion M (1993) Human development in poor countries: on the role of private incomes and public services. J Econ Perspect 7:133-150

Babones SJ (2008) Income inequality and population health: correlation and causality. Soc Sci Med 66:1614-1626

Banks J, Smith JP (2012) International comparisons in health economics: evidence from aging studies. Annu Rev Econ 4:57-81

Barro R (1999) Health and economic growth. World Health Organization

Basu S, Berkowitz SA, Phillips RL, Bitton A, Landon BE, Phillips RS (2019) Association of primary care physician supply with population mortality in the united states, 2005-2015. JAMA Intern Med 179:506-514

Batabyal AA, Nijkamp P (2020) Workplace choice, commuting costs, and wage taxation in urban and adjacent rural regions. Ann Reg Sci 65:775-786

Benson CA, Brooks JT, Holmes KK, Kaplan JE, Masur H, Pau A. (2009) Guidelines for prevention and treatment opportunistic infections in hiv-infected adults and adolescents; recommendations from cdc, the national institutes of health, and the hiv medicine association/infectious diseases society of America

Biggs B, King L, Basu S, Stuckler D (2010) Is wealthier always healthier? The impact of national income level, inequality, and poverty on public health in latin america. Soc Sci Med 71:266-273 
Brenner MH (2005) Commentary: Economic growth is the basis of mortality rate decline in the 20th century-experience of the united states 1901-2000. Int J Epidemiol 34:1214-1221

Briguglio L, Cordina G, Farrugia N, Vella S (2009) Economic vulnerability and resilience: concepts and measurements. Oxf Dev Stud 37:229-247

Catalano R, Goldman-Mellor S, Saxton K, Margerison-Zilko C, Subbaraman M, LeWinn K et al (2011) The health effects of economic decline. Ann Rev Public Health 32:431-450

Eakin H, Luers AL (2006) Assessing the vulnerability of social-environmental systems. Annu Rev Environ Resour 31:365-394

Falagas ME, Vouloumanou EK, Mavros MN, Karageorgopoulos DE (2009) Economic crises and mortality: a review of the literature. Int J Clin Pract 63:1128-1135

Ford JD, Smit B, Wandel J (2006) Vulnerability to climate change in the arctic: a case study from arctic bay, canada. Glob Environ Chang 16:145-160

Granados JAT, Ionides EL (2008) The reversal of the relation between economic growth and health progress: Sweden in the 19th and 20th centuries. J Health Econ 27:544-563

He L, Shen J, Zhang Y (2018) Ecological vulnerability assessment for ecological conservation and environmental management. J Environ Manage 206:1115-1125

Islam TMT (2020) The impact of population agglomeration of an area on its neighbors: evidence from the USA. Ann Reg Sci 65:1-26

Jackson LE, Bird SL, Matheny RW, O’Neill RV, White D, Boesch KC et al (2004) A regional approach to projecting land-use change and resulting ecological vulnerability. Environ Monit Assess 94:231-248

Karaye IM, Horney JA (2020) The impact of social vulnerability on covid-19 in the us: an analysis of spatially varying relationships. Am J Prev Med 59:317-325

Khazanchi R, Beiter ER, Gondi S, Beckman AL, Bilinski A, Ganguli I (2020) County-level association of social vulnerability with covid-19 cases and deaths in the USA. J Gen Intern Med 35:2784-2787

Kienberger S, Hagenlocher M (2014) Spatial-explicit modeling of social vulnerability to malaria in east Africa. Int J Health Geogr 13:1-16

Kunze L (2014) Life expectancy and economic growth. J Macroecon 39:54-65

Laaksonen M, Rahkonen O, Karvonen S, Lahelma E (2005) Socioeconomic status and smoking: analysing inequalities with multiple indicators. Eur J Public Health 15:262-269

Li Q, Shi X, Wu Q (2021) Effects of protection and restoration on reducing ecological vulnerability. Sci Total Environ 761:143180

Liddle B (2017) Urbanization and inequality/poverty. Urban. Science 1:35

Macharia PM, Joseph NK, Okiro EA (2020) A vulnerability index for covid-19: Spatial analysis at the subnational level in kenya. BMJ Glob Health 5:e003014

Majeed MT, Gillani S (2017) State capacity and health outcomes: an empirical analysis. Pak J Commer Soc Sci PJCSS 11:671-697

Murphy KM, Topel RH (2006) The value of health and longevity. J Polit Econ 114:871-904

Ogden CL, Fryar CD, Hales CM, Carroll MD, Aoki Y, Freedman DS (2018) Differences in obesity prevalence by demographics and urbanization in us children and adolescents, 2013-2016. JAMA 319:2410-2418

Patil RR (2014) Urbanization as a determinant of health: a socioepidemiological perspective. Social Work in Public Health 29:335-341

Rezende LF, Lee DH, Ferrari G, Giovannucci E (2020) Confounding due to pre-existing diseases in epidemiologic studies on sedentary behavior and all-cause mortality: a meta-epidemiologic study. Ann Epidemiol 52:7-14

Schaffer B, Brink M, Schlatter F, Vienneau D, Wunderli JM (2020) Residential green is associated with reduced annoyance to road traffic and railway noise but increased annoyance to aircraft noise exposure. Environ Int 143:105885

Shah NS, Lloyd-Jones DM, O'Flaherty M, Capewell S, Kershaw K, Carnethon M et al (2019) Trends in cardiometabolic mortality in the United States, 1999-2017. JAMA 322:780-782

Soylu ÖB, Çakmak İ, Okur F (2018) Economic growth and unemployment issue: Panel data analysis in eastern European countries

Spiteri J, von Brockdorff P (2019) Economic development and health outcomes: evidence from cardiovascular disease mortality in Europe. Soc Sci Med 224:37-44

Stanturf JA, Goodrick SL, Warren ML Jr, Charnley S, Stegall CM (2015) Social vulnerability and ebola virus disease in rural liberia. PLoS ONE 10:e0137208

Tapia Granados JA (2008) Macroeconomic fluctuations and mortality in postwar japan. Demography 45:323-343 
Thornton J (2002) Estimating a health production function for the us: some new evidence. Appl Econ 34:59-62

Vlahov D, Galea S (2002) Urbanization, urbanicity, and health. J Urban Health 79:S1-S12

Yousaf B, Amina LG, Wang R, Imtiaz M, Rizwan MS et al (2016) The importance of evaluating metal exposure and predicting human health risks in urban-periurban environments influenced by emerging industry. Chemosphere 150:79-89

Publisher's Note Springer Nature remains neutral with regard to jurisdictional claims in published maps and institutional affiliations. 